Retraction

\title{
Retracted: Nitroxyl (HNO): A Reduced Form of Nitric Oxide with Distinct Chemical, Pharmacological, and Therapeutic Properties
}

\author{
Oxidative Medicine and Cellular Longevity \\ Received 27 October 2016; Accepted 27 October 2016 \\ Copyright (c) 2016 Oxidative Medicine and Cellular Longevity. This is an open access article distributed under the Creative \\ Commons Attribution License, which permits unrestricted use, distribution, and reproduction in any medium, provided the \\ original work is properly cited.
}

Oxidative Medicine and Cellular Longevity has retracted the article titled "Nitroxyl (HNO): A Reduced Form of Nitric Oxide with Distinct Chemical, Pharmacological, and Therapeutic Properties" [1]. The article was found to contain a substantial amount of material from the following published articles:

(i) Nazareno Paolocci, Matthew I. Jackson, Brenda E. Lopez, Katrina Miranda, Carlo G. Tocchetta, David A. Wink, Adrian J. Hobbs, Jon M. Fukuto: The pharmacology of nitroxyl (HNO) and its therapeutic potential: Not just the janus face of NO1. Pharmacology \& Therapeutics Volume 113, Issue 2, February 2007, Pages 442-458.

(ii) Jon M. Fukuto, Michael D. Bartberger, Andrew S. Dutton, Nazareno Paolocci, David A. Wink, and, and K. N. Houk: The Physiological Chemistry and Biological Activity of Nitroxyl (HNO): The Neglected, Misunderstood, and Enigmatic Nitrogen Oxide. Chemical Research in Toxicology 200518 (5), 790-801. DOI: $10.1021 / \mathrm{tx} 0496800$.

(iii) Christopher H. Switzer, Wilmarie Flores-Santana, Daniele Mancardi, Sonia Donzelli, Debashree Basudhar, Lisa A. Ridnour, Katrina M. Miranda, Jon M. Fukuto, Nazareno Paolocci, David A. Wink: The emergence of nitroxyl (HNO) as a pharmacological agent. Biochimica et Biophysica Acta (BBA) - Bioenergetics Volume 1787, Issue 7, July 2009, Pages 835840.

(iv) Irvine, Jennifer C. et al. Nitroxyl (HNO): the Cinderella of the nitric oxide story. Trends in Pharmacological Sciences, Volume 29, Issue 12, 601-608.

(v) Katrina M. Miranda: The chemistry of nitroxyl (HNO) and implications in biology. Coordination Chemistry Reviews Volume 249, Issues 3-4, February 2005, Pages 433-455.

\section{References}

[1] M. E. Shoman and O. M. Aly, "Nitroxyl (HNO): a reduced form of nitric oxide with distinct chemical, pharmacological, and therapeutic properties," Oxidative Medicine and Cellular Longevity, vol. 2016, Article ID 4867124, 15 pages, 2016. 